\title{
Competitive Intelligence: Leaven of a New Managerial Device for Decision Support
}

\author{
Salima El Fadili*, Firdaous Gmira \\ Department of Management, Hassan 1st University of Settat, Morocco, \\ Km 3, route de Casablanca, B.P. : 784, Settat/Fax:+212 523724087 \\ *Corresponding author, e-mail: elfadili.salima@gmail.com
}

\begin{abstract}
In a highly competitive environment saturated in information traversing the earth in nanosecond, the major challenge for companies is to have the right information at the right time, to exploit it and transform it into useful organizational knowledge for strategy formulation and decision-making. Nowadays, several management practices have been developed and designed to cope with the complexity that exists in the business environment and to maintain a sustained competitive advantage. Competitive intelligence is one of these innovative strategic management practices that play an increasingly important role in decision-making. This article attempts to present an overview of its fundamental concepts, functions and process and to explain how information is utilized in supporting decision-making process. The findings of this research suggest that decision makers should focus on developing competitive intelligence process in their organizations. This paper falls under a research task that was not confronted yet with the test of the terrain survey.
\end{abstract}

Keywords: competitive intelligence, information, decision support, business intelligence, competitive advantage

Copyright $(2015$ Institute of Advanced Engineering and Science. All rights reserved.

\section{Introduction}

In today's dynamic business environment, making timely and well-informed decisions depends on an effective system of environmental scanning. This business environment is for the company the main source of uncertainty. Given this, environment scanning, wich can be considered as the predecessor of competitive intelligence $(\mathrm{Cl})$ process [1], should be a daily task for any organization looking for sustainable performance and requires from decisionsmakers some efforts of formalization. In this regard, the company should exploit changes in the environment to its advantage, therefore $\mathrm{Cl}$ is viewed as a tool that manage and takes under control these changes, provides a competitive advantage to enterprises and help decisionmakers by providing a well-focused approach that contribute to formulate optimum strategies.

Over the past few years there have been several studies wich illustrate the growing importance and role of $\mathrm{Cl}$ in business organizations. Furthermore $\mathrm{Cl}$ is a significant research area in the domain of management information systems and it is recognized by many organizations as a valuable tool to reach strategic goals, improve and increase competitiveness [2]. However, researchs on $\mathrm{Cl}$ as the foundation of strategic management are scanty [3].

The role of $\mathrm{Cl}$ - beyond mere adaptation to changes in the environment - is to reach the stage of influence on this one. In other words, thanks to $\mathrm{Cl}$ the company becomes proactive in its relationship with its environment and thus develops a level of vigilance that allows her to be more competitive. It is also considered as an organizational device and a managerial practice that contribute to a better reading of the business environment by providing strategic and relevant information that will help decisions makers to prevent threats and capitalize on the opportunities that offer their business environment, however the use of $\mathrm{Cl}$ is still at an early, fragile stage. It is underexplored and a relatively limited action within the corporate context, particularly in small and medium sized enterprises [3-5].

The growing interest in $\mathrm{Cl}$ has attracted the attention of scholars who have examined, among other topics, the impact of $\mathrm{Cl}$ on corporate performance [6]; $\mathrm{Cl}$ in small business organizations [7,8], and $\mathrm{Cl}$ process and tools $[9,10]$. Nevertheless, there is still limited Cl-related studies that explores and explain theoretically the link between $\mathrm{Cl}$ and decision making process. 
The central question posed in this paper will be how $\mathrm{Cl}$ support and lead to management decisions and action.

This research contributes to the growing $\mathrm{Cl}$ literature which aims to examine and identify the value and the role that $\mathrm{Cl}$ plays in a highly competitive business environment. In addition, this article extends previous $\mathrm{Cl}$ studies by examining its relative impact within a framework of management practices.

Therefore, this study review the current literature on $\mathrm{Cl}$ and highlight theoretically the importance of which it has in the process of decision-making by adopting a tripartite approach based on $\mathrm{Cl}$ definition, functions and process.

The remainder of this article has been structured as follows: The next section outlines the research method. The third section reviews the relevant literature on $\mathrm{Cl}$ before presenting and discussing the research results. Then followed by the conclusion and research contribution, and some proposals for further research.

\section{Research Method}

In this study, the main sources of information were books, journal including on-line journal and thesis. To identify relevant literature, academic databases and search engines were used. A review of references in related studies led to more relevant sources, the references of which were further reviewed and analyzed. Keywords such as "competitive intelligence" and "decision making process" were used in search engines to find relevant sources. To ensure reliability, only peer-reviewed articles were used.

The documents analysis was designed to gather information regarding competitive intelligence, its definitions, functions and process.

In the processing of the article have been used these methods: analysis, synthesis, deductions and comparison.

\section{Literature Review}

The business environment has become increasingly competitive day by day due to the advent of technology and certain innovations so as a result, $\mathrm{Cl}$ has become one of the significant management concepts and has been incorporated into the culture of companies.

The search for information is an old practice. It was the primary concern of decisionmakers in various fields: military, economic, political. The Japanese constitution in 1868 testifies this: "we will seek knowledge throughout the world, to strengthen the foundation of imperial rule".

The analysis of the literature allows stating that the term of "competitive intelligence" dates back to many years ago. In present study, a tripartite approach was regarded as a theoretical framework to explain the concept of $\mathrm{Cl}$. It is based essentially on an overview of its fundamentals definitions, functions and process in order to precisely describe its nature.

\subsection{Defining Competitive Intelligence}

The emergence of the concept of $\mathrm{Cl}$ involves a multiple of scientific fields and results from a number of reflections and practices. The most productive disciplines of $\mathrm{Cl}$ are information and communication sciences, business management and economic sciences [11].

$\mathrm{Cl}$, which is the research construct of this article, requires clear definition. The concepts underlying $\mathrm{Cl}$ are related to the emergence of economic power between the states and the development of trade in which strategic information was crucial and determining, sought by all countries to defend their interests and ensure their territorial and economic expansion [12].

The review of the literature on $\mathrm{Cl}$ highlighted a range of terminologies showing the evolution of concepts identifying its contours. Hereafter, we will try to highlight the evolution of this concept that have evolved rapidly in response to both changes in the business environment and managerial innovations of the company. In recent years, $\mathrm{Cl}$ has become significant in management discipline and strategic management [13].

With the advent of new information and communication technologies, $\mathrm{Cl}$ took a crucial concern among information scientists and in management science and nowadays it involves several disciplines. It generates considerable interest from scholars and as often in this type of general concepts; there is no commonly accepted definition.

TELKOMNIKA Vol. 16, No. 1, October 2015: 167 - 175 
Several definitions have been suggested to better understand the concept of $\mathrm{Cl}$. Harbulot and Baumard argue that "The $\mathrm{Cl}$ encompasses the entire competitive environment monitoring operations: scanning, protection, manipulation of information, influence" [12]. This managerial practice can be also defined as the "combined, coordinated research actions of research, treatment and dissemination for strategic and operational exploitation, useful information to economic actors. These actions are conducted legally with all the guarantees of protection necessary to preserve the company's assets, with the best quality, time and cost" [2]. In other words " $\mathrm{Cl}$ is the ability to understand the business environment and anticipate change. In this framework, it is based on the control of information and the production of new knowledge. It is a process that aims to access and convert information into knowledge, for collective learning and cooperation, in order to inform decision makers" [11].

Due to an increasingly intense competition, $\mathrm{Cl}$ is conceptualized as a "systematic process initiated by organizations in order to gather and analyze information about competitors and the general sociopolitical and economic environment of the firm" [14]. It involves a "systematic and planned process to ethically collect, analyze, synthesize and disseminate accurate, relevant, timely and actionable intelligence about customers, competitors, partners, markets and other environmental factors in order to asses and monitor external environment, provide early warning signals and support decision-makers in strategic and tactical decisionmaking" [15].

Moreover, $\mathrm{Cl}$ provides a "set of procedures and data sources used by marketing managers to sift information from the environment that they can use in their decision making" [16]. It is widely considered as a "management discipline that enables executives to make smarter, more successful decisions, thereby minimizing risk, avoiding being blind-sighted, and getting it right the first time" [17].

The Society of Competitive Intelligence Professionals (www.scip.org) propose a broader and more inclusive approach and define $\mathrm{Cl}$ as "the process of monitoring the competitive environment. $\mathrm{Cl}$ enables senior managers in companies of all sizes to make informed decisions about everything from marketing, research and development, and investing tactics to long-term business strategies. Effective $\mathrm{Cl}$ is a continuous process involving the legal and ethical collection of information, analysis that doesn't avoid unwelcome conclusions, and controlled dissemination of actionable intelligence to decision makers".

These definition points out $\mathrm{Cl}$ purpose, benefits, beneficiaries, $\mathrm{Cl}$ process, source, deliverable, ethicality and legality. The primary output from $\mathrm{Cl}$ is the ability to make forwardlooking decisions. Therefore, $\mathrm{Cl}$ drives business performance by increasing market and business environment knowledge. The most common benefit of $\mathrm{Cl}$ is its ability to build information profiles that helps a company to identify its competitor's strengths, weaknesses, objectives, strategies, market positioning and likely reaction patterns [10].

\subsection{Competitive Intelligence and Business Intelligence: Toward a Common Definition}

$\mathrm{Cl}$ is closely related to concepts such as business intelligence, marketing intelligence and environmental scanning. The biggest ambiguity is probably between business intelligence and $\mathrm{Cl}$ [15]. $\mathrm{Cl}$ and business intelligence are used at various times to describe more or less the same concept. However both have its place and both is of the utmost importance for the success of any organization.

For King business intelligence involve the use of decision support system, data warehousing technology, data mining and other business analytical tools. In other words business intelligence has a stronger focus on the technology and it is an integral part of the business intelligence process [18].

Luhn define business intelligence system as: "any communication system for conducting business in the broadest sense can be considered as an intelligence system. The concept of intelligence can be defined in a general sense, as the ability to apprehend the interrelationships between the available facts in such a way to guide action towards a desired goal" [19]. For this purpose the author proposes a system that aims to provide relevant and accurate information to support the specific activities of the company. This is an automatic system designed to provide software solutions enabling the company to operate its stock of information via a well-defined process in order to produce relevant and actionable information [20]. This system is called business intelligence system.

Competitive Intelligence: Leaven of a New Managerial Device for Decision... (Salima El Fadili) 
According to Albescu et al. "business intelligence is the activity of monitoring mostly the internal business processes, while $\mathrm{Cl}$ is focused on the monitoring of external environment and uses public resources to locate and develop information on competition and competitors" [21].

If we refer to the data sources, we can see that business intelligence uses primarily data from inside the company. Most business intelligence data is structured data. $\mathrm{Cl}$ uses information from outside the company and is never sure that all relevant data sources are being captured. In others words, a business intelligence system is based on intensive database as well as information technology tools; it refers to the software used to manage a flow of data. Whereas $\mathrm{Cl}$ is the action of gathering, analyzing, and distributing information about the environment needed to support managers in making strategic and tactical decisions.

Moreover, $\mathrm{Cl}$ is the analytical process that transforms information about the firm environment (competitors, customers, suppliers) into relevant, strategic and actionable information on market evolution, business opportunities and threats, nevertheless most information within the $\mathrm{Cl}$ environment is unstructured, which emphasizes the complementarities of business intelligence and $\mathrm{Cl}$. In addition, $\mathrm{Cl}$ process requires skills in strategic thinking, extensive analytical abilities and scientific analytical methodologies. The common target between $\mathrm{Cl}$ and business intelligence is to support management decision-making that leads to action. The main differences between business intelligence and $\mathrm{Cl}$ are described in Table 1:

Table 1. The basic differences between business intelligence and competitive intelligence [21]

\begin{tabular}{lll}
\hline & \multicolumn{1}{c}{ Business intelligence } & \multicolumn{1}{c}{ Competitive intelligence } \\
\hline Purpose & $\begin{array}{l}\text { Analyzing mostly of the internal } \\
\text { business processes, improvement } \\
\text { operational and tactical decisions }\end{array}$ & $\begin{array}{l}\text { Monitoring, analyzing of external environment, } \\
\text { customers, suppliers, competitors, increasing strategic } \\
\text { decisions }\end{array}$ \\
Scope & Organization & Environment of organization \\
Content/data & $\begin{array}{l}\text { Well structured content, internal data } \\
\text { coming from data bases, ERP, trans- }\end{array}$ & $\begin{array}{l}\text { Semistructured, unstructured content, external data } \\
\text { action systems } \\
\text { Used tools, } \\
\text { technologies }\end{array}$ \\
OLAP, data mining, data warehouse & $\begin{array}{l}\text { Advanced data mining, predictive model-ing, web } \\
\text { mining, text mining, agent technology, exponential } \\
\text { random graph models, search based application. }\end{array}$ \\
\hline
\end{tabular}

For Olszak business intelligence is a subset of $\mathrm{Cl}$, it provides a balanced picture of the business environment to the decision makers by gathering and analyzing relevant informations about the behaviors of the market actors [22]. In other words, $\mathrm{Cl}$ is having both internal and external components and relies heavily on external information; thus, that is why $\mathrm{BI}$ - with its internal focus- is subsumed within $\mathrm{Cl}$.

\subsection{Competitive Intelligence Functions}

Drawing on the work of Larivet [23] and Levet [24], we present in what follows a theoretical approach of the functions of $\mathrm{Cl}$ most cited and most considered in the literature.

Larivet [23] lists three main functions of the Cl:

\section{a) Strategic monitoring/scanning}

One of the most talked dimensions of $\mathrm{Cl}$ is strategic monitoring, the concept drew on the heritage of "industrial espionage" and often confused with it.

According to Brouard organizations should scan the environment in which they operate to ensure that they are ahead of the changes that are happening in their industry, and they are aware of what their competitors are doing in order to react quickly if and when necessary [25]. This function aims to learn continuously on the environment, it involves the research, gathering, storage, analysis, dissemination and the use of this analyzed intelligence in strategic decisionmaking.

b) The protective function or information risk management

The abundance of information and easy access to a huge array of data has led to a growing uncertainty surrounding the business environment, and no company operating in such context can consider itself immune to information risk. 
Described as information risk management, this function has the purpose to preserve the information assets of the organization. It is in this context that Juillet emphasized the importance of this function by stating: "Cl consists of the mastery and protection of strategic information to every economic actor" [26]. This definition underscores an essential point: information protection and security. Thus Larivet notes that $\mathrm{Cl}$ is designed to protect information held or issued by the company to preserve the informational asymmetry in favor of the company [11].

\section{c) The influence function}

By expanding into a fast- moving society and in an open global market, information is becoming a strategic value driver and is considered as a lever of influence. For this reason $\mathrm{Cl}$ aims to create an influencing strategy in order to achieve better outcomes and have much control on the environment. This dimension has become crucial in the $\mathrm{Cl}$ field of action and aimed to wield an informational pressure by positively altering the interaction of the company with its environment.

\subsection{Competitive Intelligence Process}

$\mathrm{Cl}$ is a dynamic process consisting of interrelated phases [27]. The output of each phase is the input to the next phase [28]. The result of $\mathrm{Cl}$ process is dessiminated to decision makers to act upon it. There is many $\mathrm{Cl}$ process models described in the literature.

According to Weiss, there are four stages in scanning the company environment especially competitors monitoring, called the four "C", described in Figure 1 [29]:

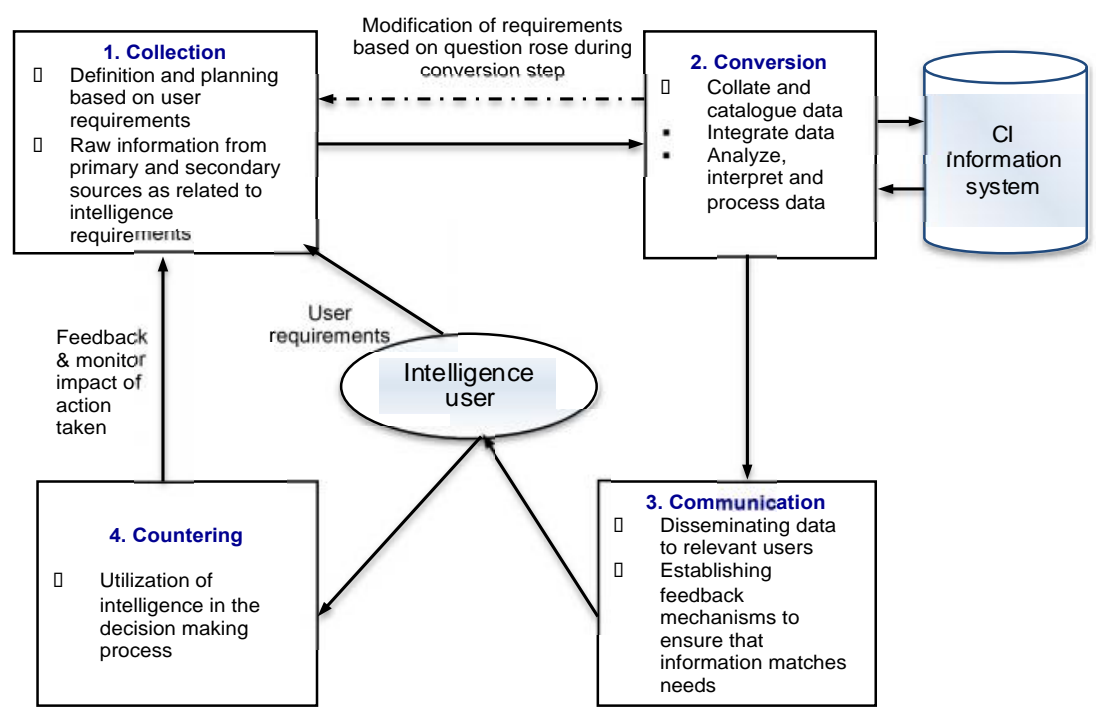

Figure 1. The 4"C" approach of competitive intelligence [29]

This 4 "C" approach of $\mathrm{Cl}$ consists of the following substages:

a) Collecting the information based on user requirement;

b) Converting information into intelligence;

c) Communicating the intelligence to users specially decisions makers;

d) Countering any adverse competitor actions (making use of gathered intelligence) by outlining the feedback from decision-makers.

This $\mathrm{Cl}$ process aims to provide actionable intelligence during the analysis phase that will build and maintain a competitive edge to the company.

Viewed from a scientific angle, David states 7 steps of the competitive intelligence process [30]:
a) Identification of a decision problem;
b) Translation of the decision problem into an information search problem;
c) Identification of relevant information sources; 
d) Collection of relevant information from the external environment in an ethical and legal manner;

e) Analysis of the information collected to extract indicators for the decision;

f) Interpretation of indicators;

g) Decision-making.

Utilising Competitive Intelligence successfully in the organization doesn't stand only for a clearly elaborated process. The required framework conditions such as organizational culture and awareness, a formal infrastructure and employee involvement should exist in order to ensure successful and effective implementation.

All corporate management processes and structure that might affect the $\mathrm{Cl}$ process implementation must be considered throughout the $\mathrm{Cl}$ process.

\subsection{Competitive Intelligence as a Decision Support Device}

The term of "decision support" is used widely and in a variety of contexts related to decision making process. It is a broad term that encompasses all aspects related to assisting organizations in making decisions.

Specifically, decision support system encompasses many types of information systems that support decision making including business intelligence tools.

In all types of enterprises, decisions makers face difficult and complex situations in which they must make major decisions so that they can adapt to the changes in the business environment in which they operate. This implies a critical need for strategic focus on competitive analysis which critically depend on proper and effective $\mathrm{Cl}$ system.

$\mathrm{Cl}$ as a support decison device enhance acces to relavant and accurate information which is a vital elemnt of decison making process.

Decision-makers can extract from raw information flowing in the environment of the organization actionable intelligence and knowledge in order to support decision-making. This decision support process could make use of technologies and analytical tools such as Intranets or data warehouses etc, that assists in making decisions process by making accurate, current and relevant information available as required by managers.

The decison support phase, which is considered as the most important step in $\mathrm{Cl}$ process, is finished by making some intelligence products which take the shape of some outputs: daily reports, strategic impact analysis, risk and opportunities bulletin. The ability to perform appropriate transformation and interpretation of raw information is a vital element for the success of the decision making process.

The overall output of the competitive intelligence process is an input to the decisionmaking process. Figure 2 outlines the contribution of $\mathrm{Cl}$ in decision support by revealing how information from disparate sources can be exploited to be retrieved for analysis so one can make better, founded and informed decisions for enhancing competitiveness of organization.

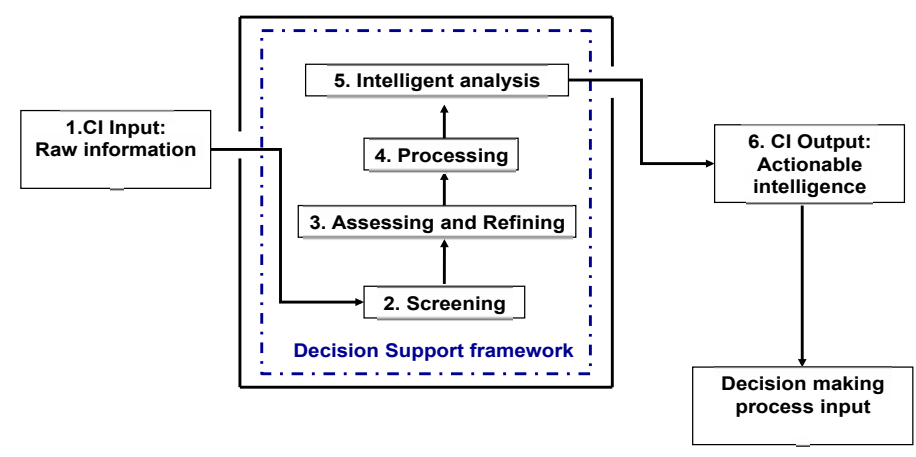

Figure 2. From $\mathrm{Cl}$ input to decision making process input

Moreover, $\mathrm{Cl}$ is viewed as a way and method of improving business performance by reducing the uncertainty in the decisions making process that benefit the organization and providing further support and assistance to decision makers in order to allow them to have

TELKOMNIKA Vol. 16, No. 1, October 2015: $167-175$ 
actionable intelligence at hand. Furthermore, $\mathrm{Cl}$ enables firms to make fast, better, and wellinformed business decisions and thus can be the source of competitive advantages.

As depicted above $\mathrm{Cl}$ provides a means for extracting information from the clutter that would be useful for decision-making goals and its major purpose is to support management decision-making that will influence strategic benefits expansion in organization and subsequently provide a sustainable competitive edge to the organization.

\section{Results and Discussion}

So far, most of scholars concentrated their studies on empircal analysis to explore and assess the impact of $\mathrm{Cl}$ practices on business performance. Therefore focus on theoritical foundations of $\mathrm{Cl}$ is much needed. Given this, in this paper, an in depth theoretical overview has lead to the following results:

The world of data has changed in the last years, for this reason the organizations need to think creatively about the potential of new, external data sources. Managers do not always know how such sources can be effectively used and exploited in decision making process.

According to the proponents of decision theory, the decision-makers are far from having all the information that would make from their decisions rational acts. The decision theory authors emphasize the uncertainty of the decision due to a lack of information or ambiguous decisions in case of plethora information [31]. To overcome this complexity in the process of decision-making, $\mathrm{Cl}$ is considered, on the one hand, as a monitoring approach that detect opportunities and threats and effectively adapt to changes in the environment, and on the other hand, as a organizational learning process and a tool for solving decision problems. In other words, $\mathrm{Cl}$ affects a wide range of areas of decision-making, and it is a vital ingredient for the formulation of business strategy. Top management must plan, support and implement a $\mathrm{Cl}$ process [32].

For Levet, this increasing complexity surrounding the business environment was at the origin of the emergence of a "real need of lighting the decision making by information" [24]. For this reason an effective $\mathrm{Cl}$ system is required to helps enterprises to improve their performance [33].

Based on all of the definitions of $\mathrm{Cl}$ outlined above, it appears that the information remains the cornerstone of any competitive intelligence system. Thus all $\mathrm{Cl}$ approach aims to collect, process and interpret effectively the content of the relevant information from the business environment that is needed by different levels of decision. It aims also to provide help in decision-making and to provide an enterprise with a competitive advantage.

There are many definitions of $\mathrm{Cl}$ in the literature [34] and none has achieved worldwide acceptance. In others terms, there is therefore no definition that is comprehensive, most definitions focus only on certain aspects of $\mathrm{Cl}$, leaving out others.

Based on its definition, functions and process $\mathrm{Cl}$, as an information management practice, can be defined as a sequential process linking information to decision and strategic action and ensuring permanent monitoring of the business environment, as well as protection of relevant information, and developing a capacity of influence that enables the organization to shape the environment in its favor in order to improve its competitive position.

All previous scholars presente $\mathrm{Cl}$ in a cycle of phases. The reason behind the use of a cycle is that the $\mathrm{Cl}$ process never stops, but is continuous. The output of each phase is the input to the next phase [28]. The overall output of the $\mathrm{Cl}$ process is an input to the decision-making process [35]. In others words, the ultimate goal of $\mathrm{Cl}$ practices is to facilitate effective decision making that leads to actions.

In an environment characterized by complex and dynamic changes that are reflected through the uncertainty and risk in business, the need of analysis of the decision-making situations is increasingly felt. To cope with this environment complexity $\mathrm{Cl}$ enables reconfiguring the process of decision-making based on the appropriation and interpretation of information in a collaborative, selective and offensive approach. It is a process that helps to better understand the decision-making problems within an organization. Therefore, it is necessary to develop an appropriate organisational awareness of $\mathrm{Cl}$ and to build an information culture within the organization .

According to the literature analysis made in this research paper, $\mathrm{Cl}$ should be considered, on the one hand, as a corporate culture that encourages organizational learning

Competitive Intelligence: Leaven of a New Managerial Device for Decision... (Salima El Fadili) 
and knowledge sharing and on the other hand, as an ability and an approach, nay even being "a mode of action and a way of thinking" [24].

\section{Conclusion}

The purpose of this research was to review the current literature on $\mathrm{Cl}$ with the aim of identifying and analyzing $\mathrm{Cl}$ definitions, functions and process and particularly its contribution in decision making process.

In today's highly competitive business environment, $\mathrm{Cl}$ has undergone a raising interest in recent years as a result of the information explosion and it has experienced a rapid growth over the past years to become an integral part of most large organizations. The mere fact of holding the information is by no means sufficient to distinguish themselves from the competition, what matters is how $\mathrm{Cl}$ uses wisely and efficiently the resources and capabilities of the company to develop a strategy that links information to action. It is in this sense that Guilhon and Levet state that $\mathrm{Cl}$ cannot be reduced to simple information flow management function, but rather a conversion of this flow of information into knowledge and skills and therefore competitive advantages [36].

This paper has sought to contribute further to the knowledge concerning competitive intelligence as a managerial concept. Some opportunities for future research emerge, including detailed, empirical tests and theoritical reflexion on information tools for $\mathrm{Cl}$ building should be conducted so further empirical and theoritical investigations and precise validations are invited to explore the associations between $\mathrm{Cl}$, capabilities and strategic orientations of the organizations.

\section{References}

[1] Calof JL, Wright S. Competitive intelligence: a practitioner, academic and inter-disciplinary perspective. European Journal of Marketing. 2008; 42(7/8): 717-730.

[2] Martre $\mathrm{H}$. Intelligence économique et stratégie des entreprises. Commissariat général du Plan. La documentation française.1994.

[3] Mohsin AA, Halim HA, Ahmad NH. Competitive Intelligence Among SMEs: Assessing the Role of Entrepreneurial Attitude Orientation on Innovation Performance. In Innovation, Finance, and the Economy. Springer. 2015; 1: 15-22.

[4] Salles M. Decision making in SMEs and information requirements for competitive intelligence. Production Planning \& Control. 2006; 17(3): 229-237.

[5] Larivet S, Brouard F. SMEs' attitude towards SI programmes: evidence from Belgium. Journal of Strategic Marketing. 2012; 20(1): 5-18.

[6] Cohen C. Intelligence et Performance mesurer l'efficacité de l'Intelligence Economique et Stratégique (IES) et son impact sur la Performance de l'Organisation. Vie \& sciences de l'entreprise. 2007; 174(1): $15-50$.

[7] Guimaraes T. The impact of competitive intelligence and IS support in changing small business organizations. Logistics Information Management. 2000; 13(3): 17-125.

[8] Magasa L, Mphahlele MI, Awosejo OJ. Utilization of Competitive Intelligence to Enhance Firm Performance: A Case of South African Small and Medium Enterprises. International Journal of Advanced Computer Research. 2014; 4 (2): 555-559.

[9] Deschamps C, Moinet N. La boîte à outils de l'intelligence économique. Dunod. 2011.

[10] Bose R. Competitive intelligence process and tools for intelligence analysis. Industrial Management \& Data Systems. 2008; 108(4): 510-528.

[11] Larivet S. Intelligence économique: enquête dans 100 PME. Editions L'Harmattan. 2009.

[12] Harbulot C, Baumard P. Perspective historique de l'intelligence économique. Intelligence Economique. 1997; 1: 1-17.

[13] Zangoueinezhad A, Moshabaki A. The role of structural capital on competitive intelligence. Industrial Management \& Data Systems. 2009; 109(2): 262-280.

[14] Colakoglu T. The Problematic Of Competitive Intelligence: How To Evaluate \& Develop Competitive Intelligence?. Procedia-Social and Behavioral Sciences. 2011; 24: 1615-1623.

[15] Haataja JE. Social media as a source of competitive intelligence in a pharmaceutical corporation. Master's thesis. School of Science, Aalto University; 2011.

[16] Nasri W, Charfeddine L. Motivating salespeople to contribute to marketing intelligence activities: An expectancy theory approach. International Journal of Marketing Studies. 2012; 4(1): 168-175.

[17] Nikolaos T, Evangelia F. Competitive intelligence: concept, context and a case of its application. Science Journal of Business Management. 2012; 2012(2): 1-15.

[18] King WR. Knowledge management and organizational learning. Springer. 2009.

TELKOMNIKA Vol. 16, No. 1, October 2015: 167 - 175 
[19] Luhn HP. A business intelligence system. IBM Journal of Research and Development. 1958; (2)4: 314-319.

[20] Moinet N. Petite histoire de l'intelligence économique: une innovation à la française. Editions L'Harmattan. 2010.

[21] Albescu F, Pugna I, Paraschiv D. Business intelligence \& knowledge management-Technological support for strategic management in the knowledge based economy. Revista Informatica Economică. 2008; 4(48): 5-12.

[22] Olszak CM. An Overview of Information Tools and Technologies for Competitive Intelligence Building: Theoretical Approach. Issues in Informing Science and Information Technology. 2014; 11: 139-153.

[23] Larivet S. L'intelligence économique: étude de cas d'une pratique managériale accessible aux PME. actes du 8ème CIFEPME. 2006: 24-27.

[24] Levet JL. L'intelligence économique: mode de pensée, mode d'action. Economica. 2001.

[25] Brouard F. Development of an expert system on environmental scanning practices in SME: tools as a research program. Journal of Competitive Intelligence and Management. 2006; 3(4): 37-58.

[26] Juillet A. Référentiel de formation en intelligence économique. Secrétariat général de la défense nationale. 2005.

[27] Nasri W. Investigate Competitive Intelligence Process: An Exploratory Study in Tunisian Companies. International Business Research. 2011; 4(4): 62-73.

[28] Bartes F. Increasing the competitiveness of company by competitive intelligence. In 7th International Scientific Conference Business and Management. Vilnius Lithuania. 2012: 10-11.

[29] Weiss A. A brief guide to competitive intelligence: how to gather and use information on competitors. Business Information Review. 2002; 19(2): 39-47.

[30] David A. Regard scientifique sur le concept d'intelligence économique. In La Veille sur l'Internet du libre accès: entre objet scientifique réflexif et management stratégique de l'information économique. 2007.

[31] L Rouleau. Théories des organisations: approches classiques, contemporaines et de l'avant-garde. Puq. 2007.

[32] Nasri W. Competitive intelligence in Tunisian companies. Journal of Enterprise Information Management. 2011; 24(1): 53-67.

[33] Lackman C, Lanasa JM. Competitive Intelligence and Forecasting Systems: Strategic Marketing Planning Tool for SME's. Atlantic Marketing Journal. 2013; 2(2): 1-14.

[34] Weiss A, Naylor E. Competitive intelligence: How independent information professionals. American Society for Informafion Science and Technology. 2010; 37(1): 30-34.

[35] Bartes F. Defining a Basis for the New Concept of Competitive Intelligence. Acta Universitatis Agriculturae et Silviculturae Mendelianae Brunensis. 2015; 62(6): 1233-1242.

[36] Guilhon G, Levet JL. De l'intelligence économique à l'économie de la connaissance. Economica. 2003. 